\title{
The added value of a Central Agency of European Debt
}

\author{
Georges HÜBNER \\ HEC Management School -- University of Liège (Belgium) \\ School of Business and Economics, Maastricht University (the Netherlands) \\ Gambit Financial Solutions (Belgium)
}

Robert JOLIET

IESEG School of Management Lille-Paris, France (LEM-CNRS)

\begin{abstract}
In this paper, we examine the opportunity to create a Central Agency of European Debt (CAED) to improve the coordination between the issuances of sovereign debt in the EMU, by allowing the Agency to issue euro - bonds and determine the optimal proportion of foreign currency denominated debt and the corresponding maturity at the EMU level. We argue that this Agency could decrease both the overall cost of sovereign debt at the EMU level and the cost of sovereign debt of the individual EMU countries, including the strongest members (Germany, the Netherlands). Such a mechanism requires four economic conditions: a collective guarantee by members for the euro-bonds, a marking-tomarket process for each individual member, a seniority of existing sovereign debt, and an internal sovereign swap market between the members of this Agency.
\end{abstract}

\section{Introduction}

The 2010 sovereign debt crisis in Europe, and more particularly the Greek crisis, has brought to light the strengths but also the failures of the Economic and Monetary Union (EMU). Without the euro as single currency and without the rescue mechanism set up by the European countries, Greece would presumably have defaulted on her debt, because of the very high risk premium required by investors, potentially dragging several other European countries down with her.

The issuance of "Euro-bonds", an idea that was raised amidst the second wave of the sovereign financial crisis of 201011, may reduce the borrowing cost of the most troubled countries, but it has been fiercely rejected by a good deal of member countries of the EMU. The main concern was that, even though the benefit of such an issue could be collectively warranted, the credit spread that investors would require on such bonds would exceed the one of the best rated countries, especially Germany and the Netherlands.

Even though the decision to issue such bonds or not is a political one, the discussion of cost savings that could be obtained using such a mechanism belongs to the field of economic analysis. The aim of this paper is to provide a comprehensive insight on the benefits from a Central Agency of European Debt (CEAD) coordinating the sovereign bond issuance at the EMU level. We show that both the most troubled countries and the strongest countries, such as Germany and the Netherlands, can benefit from the mechanism proposed in this paper.

The paper is organized as follows. The first section of this paper deals with the principle of coordinating the issuance of sovereign debt at the EMU level through a CAED. The second section presents the structure of the CAED functioning. The third section identifies the cost saving potential. Section four discusses the conditions for sustainability. A concrete case study is provided in section five and section six concludes the paper.

\section{Principle}

Pooling bond issuance within a consortium and endowing a separate body with the right and responsibility of issuing bonds on behalf of the consortium can be related to a cost-benefit analysis performed by Hübner and Joliet (2011). 
According to their approach, the optimal government debt mix between domestic and foreign debt (in terms of currency denomination) results from the trade-off between the components of the corresponding spreads.

\subsection{Trade-off between the spread components}

Since the introduction of the EMU, the yield spread between the bond issued by an European country and the benchmark bond considered as the safest profile - generally the German Bund with the same maturity - has been determined by two dominant factors: the spread associated with the default risk of the issuer, and the spread associated with the liquidity risk of the bond; the first one being originally the most dominant in the EMU, as reported in Table 1 for the 10-year benchmark government bond issued in euro.

\begin{tabular}{ccccc}
\hline \hline & $\begin{array}{c}\text { Average } \\
\text { Default } \\
\text { spread } \\
(2000)\end{array}$ & $\begin{array}{c}\text { Average } \\
\text { liquidity } \\
\text { spread } \\
(2000)\end{array}$ & $\begin{array}{c}\text { Average } \\
\text { default } \\
\text { spread } \\
(2010)\end{array}$ & $\begin{array}{c}\text { Average } \\
\text { liquidity } \\
\text { spread } \\
(2010)\end{array}$ \\
\hline Austria & 29.31 & 0.1 & 42.11 & -2.65 \\
Belgium & 33.93 & -1.0 & 48.77 & 17.9 \\
Finland & 17.82 & 2.10 & 12.81 & 9.60 \\
France & 15.11 & 1.0 & 32.17 & 1.4 \\
Ireland & 11.79 & 5.3 & 295.14 & 2.2 \\
Italy & 36.26 & -2.3 & 121.29 & 1.3 \\
Netherlands & 13.19 & 1.1 & 12.41 & 10.0 \\
Portugal & 32.01 & 2.2 & 245.82 & 6.0 \\
Spain & 23.57 & 3.0 & 143.1 & 6.8 \\
\hline \hline
\end{tabular}

Table 1: Average default and liquidity yield spreads for the 10-year benchmark euro government bond in 2000 and 2010 . Numbers are in basis points. The default spread is the difference between the total yield spread and the liquidity spread. The latter is based on the difference on spreads between the yields of the on-the-run and off-the-run 10-year benchmark bonds. Source: authors' computations from Datastream \& Bloomberg databases.

From Table 1, we observe that in 2000, the default spread was the predominant factor in the total yield spread, with Ireland, Finland and the Netherlands exhibiting the lowest default spreads. The average liquidity spread is relatively low, which supports Gomez-Puig (2006), and Manganelli and Wolswijk (2007) who report the existence of a liquidity risk premium, but default risk is definitely the main factor. For some countries, the average liquidity spread is almost insignificant, which corroborates Favero at al. (2010) who show that liquidity differentials are only priced for a subset of the euro-zone bond markets.

The sovereign debt crisis in 2010 has slightly changed this situation for Finland and the Netherlands for which the average default spread is quite stable, but now similar to the average liquidity spread. These two countries have still the lowest average default spread, suggesting a relative strong demand for these bonds over the limited bond supply. Beber et al. (2009) also find that liquidity plays a non-trivial role, especially for low credit risk countries and during times of heightened market uncertainty. Ireland and Southern countries (Portugal, Spain and Italy) exhibit the higher average default risk premiums. The difference in credit spreads is very significant compared to the other countries.

Without the EMU, the spreads of these countries would probably have been more substantial. The Irish, Portuguese, Spanish and Italian spreads would also have been determined by a foreign exchange risk factor and an inflation risk factor, since surprise inflation and/or the devaluation of the national currency would have threatened directly or indirectly the market value of sovereign debt.

As an illustration, Figure 1 depicts the evolution of Belgium's currency risk yield spread before the introduction of the euro from 1994 to 1998. This component is generally approximated as the spread between the swap rate in Belgian franc and the swap rate in German mark for the same maturity (see Favero 1997, Codogno et al. 2003, and Gomez-Puig 2008). 


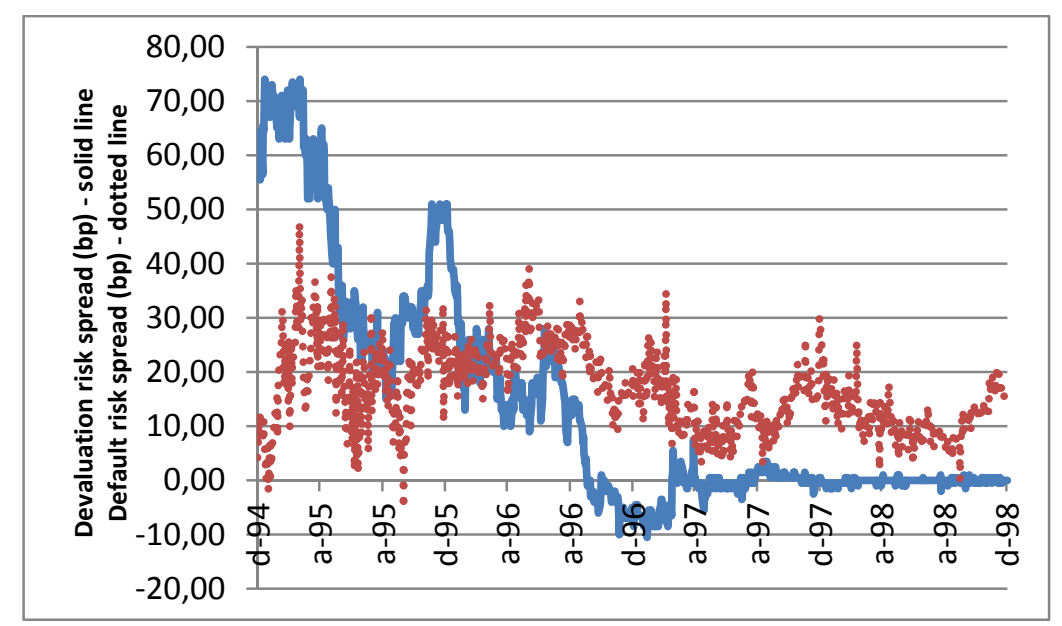

Figure 1: Evolution of the daily devaluation risk (solid line) and default risk (dotted line) yield spreads of Belgium for the 10-year benchmark Government bond over the 1994-1998 period. Devaluation risk spread is approximated as the difference between the swap rate in Belgian franc and the swap rate in German mark for the same maturity. Default spread is measured as the difference between total yield spread and devaluation spread, minus the liquidity spread. Numbers are in basis points. Source: authors' own computations from Datastream and Bloomberg.

Figure 1 clearly shows that the currency risk spread was the main factor before the introduction of the euro, which is consistent with Favero et al. (2010). This spread converges toward zero as the advent of the EMU approaches. Once the euro has been introduced, there is no longer devaluation risk spread, since the withdrawal of a country from the euro zone was not provided for by the Maastricht treaty. The default risk spread becomes the dominant risk spread component.

\subsection{Need for a coordination of debt issuance policy}

If the EMU is able to play a significant role as a shield against devaluation risk, the rescue plan set up by the European countries in 2010, though against the spirit of the treaty of Maastricht, translates inevitably a failure for the EMU: the lack of a European common budgetary and economic policy. If countries belonging to the EMU are no longer free to play on currency devaluation and inflation, national governments can still issue sovereign debt freely on their own, with specific maturities and currency denominations which are appropriate for them. It can be deemed as paradoxical: The monetary policy and the commitment to stable inflation are coordinated at the European level by the European Central Bank (ECB), while national governments can indirectly impact on inflation and the euro exchange rate throughout their diverse issues of national debt realized in an independent way and without coordination with the other countries and the ECB. The euro exchange rate and the European inflation are two important factors in the determination and the structure of the cost of sovereign debt, both in euro and in foreign currencies. The inflation is clearly influenced by the evolution of the total amount of debt, but also by the proportion of debt issued in euro. In the same vein, the exchange rate of the euro is affected by the proportion of debt issued in euro by the indirect effect of the European inflation, but also by the stimulus created by the possible depreciation. But debt issuances by other European countries are never taken into account simply because every country is sovereign.

Certainly, the convergence criteria of the treaty of Maastricht induce every country of the EMU to control its public deficits, as well as his debt levels over GDP. However, the experience and the financial crisis showed that these criteria were above all relative and certainly not binding condition in any circumstances.

On the basis of their framework and using a game-theoretic argument, Joliet and Hübner (2011) confirm the finding of Nielsen (1999) that it is more efficient for each individual country to endow a central Agency with the capacity to choose the optimal mix of currencies and maturities on behalf of the member states rather than each country pursuing their issuance policy in a selfish manner.

The core of the argument rests on the characterization of each country's optimal behavior when considered in isolation. Depending on the dynamics of their default spread, which would ceteris paribus affect foreign debt to a greater extent than domestic debt, sovereign issuers have an incentive to fully issue domestic or foreign debt. If, instead, the decision to issue debt resulted from the objective a achieving a Pareto-optimal solution to the same Nash game, then one would presumably avoid corner solutions.

In Table 2, we examine how the ratio of foreign debt to total marketable debt evolves over time for the initial member countries of the EMU. 


\begin{tabular}{cccccc}
\hline \hline & average & start & end & Trend/year & $\mathrm{R}^{2}$ \\
\hline Austria & $8,33 \%$ & $14,52 \%$ & $2,26 \%$ & $-1,30 \%$ & 98.3 \\
Finland & $4,50 \%$ & $16,61 \%$ & $0,00 \%$ & $-1,78 \%$ & 65.8 \\
Portugal & $2,57 \%$ & $7,32 \%$ & $1,81 \%$ & $-0,62 \%$ & 49.1 \\
Spain & $2,23 \%$ & $3,92 \%$ & $1,19 \%$ & $-0,31 \%$ & 85.7 \\
Italy & $1,66 \%$ & $3,95 \%$ & $0,11 \%$ & $-0,42 \%$ & 93.3 \\
Ireland & $1,24 \%$ & $6,91 \%$ & $0,00 \%$ & $-0,56 \%$ & 45.1 \\
Belgium & $0,75 \%$ & $2,00 \%$ & $0,04 \%$ & $-0,17 \%$ & 56.7 \\
Netherlands & $0,63 \%$ & $0,00 \%$ & $1,76 \%$ & $0,24 \%$ & 47.8 \\
Germany & $0,24 \%$ & $0,00 \%$ & $0,25 \%$ & $0,06 \%$ & 61.5 \\
Greece & $0,23 \%$ & $0,00 \%$ & $0,32 \%$ & $0,06 \%$ & 43.5 \\
France & $0,00 \%$ & $0,00 \%$ & $0,00 \%$ & $0,00 \%$ & N/A \\
Luxembourg & $0,00 \%$ & $0,00 \%$ & $0,00 \%$ & $0,00 \%$ & N/A \\
\hline \hline
\end{tabular}

Table 2: statistics of the ratio foreign marketable debt / total marketable debt for the first 12 EMU member countries for the period 2000-2010. Source: OECD’s iLibrary http://stats.oecd.org

Countries are ranked from highest to lowest average foreign debt ratio. The first seven ones experience a steady decrease in the ratio over time, with a significant explanatory power of a simple linear regression trend. These countries tend to behave as if they were systematically refinancing their maturing foreign debt (outstanding before the EMU advent) by debt denominated in euro. This finding confirms the prediction of Hübner and Joliet (2011), and leads to corner solutions at all domestic debt for all member countries.

Within this context, the aim of the CEAD should be to reproduce the potential cooperative behavior of member states regarding their decision to mix domestic and foreign debt. ${ }^{1}$ The task of the Agency indeed has to go beyond a simple mission of information about the issuance policy of each government. It must be able to determine, at the level of the $E M U$, the optimal total proportion of debt that must be issued in euro and in foreign currencies, in order to minimize the cost of debt accordingly.

Figure 2 illustrates the paradox of the policy issuance within the EMU. As all governments belonging to the EMU select corner solutions by increasing the proportion of debt denominated in euro, the proportion of foreign debt at the EMU level automatically decreases. The figure plots this proportion of foreign debt as a function of the euro effective exchange rate (denominator is the euro) for the period 2000-2010.

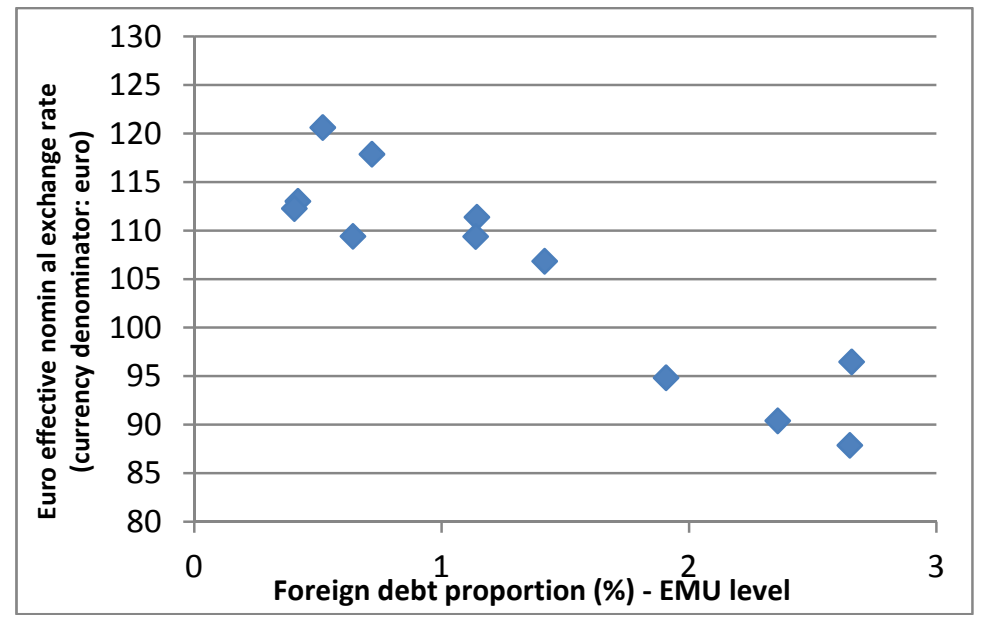

Figure 2: Proportion of foreign debt as a function of the euro nominal effective exchange rate (denominator is the euro) against EER40 group of trading partners for the 2000-2010 period. Exchange rate data come from the ECB and the proportion of foreign debt at the EMU level is computed by the authors based on data from OECD.

In the figure, we observe that the stronger the euro, the lower the proportion of foreign debt, which is intuitive and consistent. This example is simply stylized fact, of course, because it notably omits the interaction with other variables, such as the structure of default spreads, but it illustrates nevertheless the point that selfish and independent issuances are

\footnotetext{
${ }^{1}$ Hübner and Joliet extend the reasoning to the choice of debt maturities, but the discussion goes beyond the case studied in this paper.
} 
not coordinated with factors managed independently by the ECB. The proportion of foreign debt at the EMU level is the result of a simple aggregation of foreign debt issued by each government and not from optimality.

The absence of coordination does not imply that the proportions of foreign debt observed in Figure 1 are optimal, in terms of cost minimization. The Agency should therefore determine this optimal proportion. From that point, every national government will have the faculty to determine, in an optimal way, depending on its own cost structure, which is its part in the global amount of debt issued in euro and in currencies that will minimize its own cost of debt. The CAED will have determined definitively, at the European level, the effect of debt issuances in euro and in currencies on the euro exchange rate and on the European level of inflation. This ensures, at the same time, a better action of the ECB for its monetary policy, and an optimal policy of government bond issues, not only at the level of the EMU, but also at the national level.

To this end, the Agency does not substitute to the member states regarding their decisions of how much debt they want to issue and with what target maturity. Rather, it should be in charge of applying these decisions through a debt issuance program.

\section{Mechanism}

Consider a simplified situation in which two countries belong to the same currency zone, and all amounts are converted to this domestic currency. Country 1 has a better rating than country 2. They have independently set their optimal debt level and currency mix to $\mathrm{D}_{1}$ and $\mathrm{F}_{1}$ and $\mathrm{D}_{2}$ and $\mathrm{F}_{2}$, respectively. By directly accessing the bond markets in domestic and foreign currencies, they can observe the market yield on each type of debt.

The mechanism is represented schematically in Figure 3. Each country decides to withdraw part of the existing debt, and asks the CAED to issue an amount corresponding to the amount retired. The choice of the mix between domestic and foreign debt, respectively for notional amounts $\mathrm{D}^{*}$ and $\mathrm{F}^{*}$, is left to the discretion of the Agency. It decides in such a way to minimize the aggregate cost of the issue. Each country's aggregate funding requirement is reconciled through the identity between the amount issued by the CAED and the total debt withdrawn by the members of the consortium.

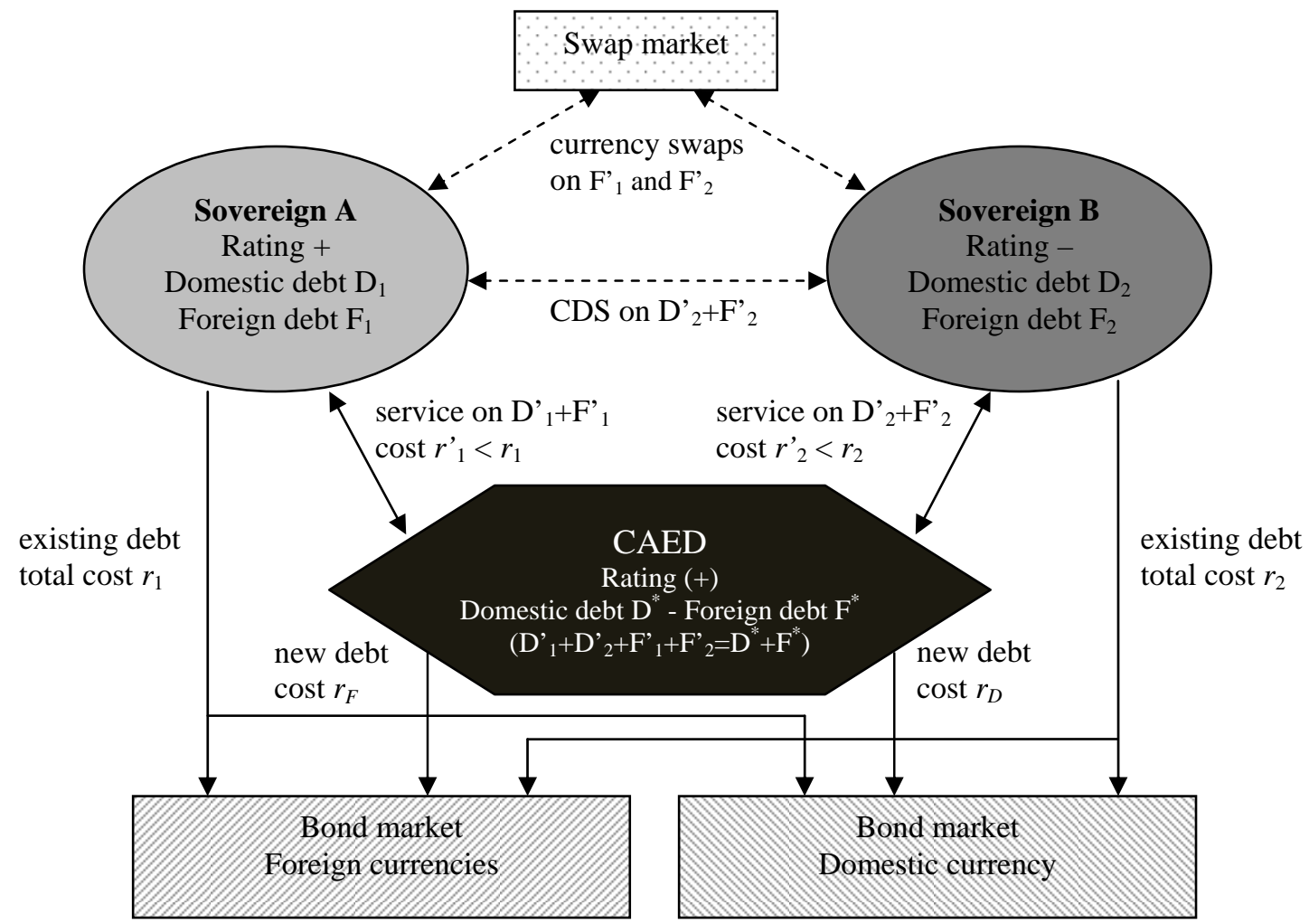

Figure 3: schematic structure of the CAED functioning

The proceeds from the issues are immediately transferred to the governments proportionally to their commitment. The foreign part is immediately converted into the domestic currency, and the cost of servicing the foreign part is obtained through a plain vanilla currency swap organized by each country’s government. 
The following simplified example illustrates the process and emphasizes the potential for value creation. Countries A and B want to issue 1 Billion debt with a maturity of 10 years. They both find it favorable to issue $90 \%$ domestic debt and $10 \%$ foreign debt. The par coupon yield of such debt for A is $4 \%$ and for B is $5 \%$. To keep the example simple, the yield is the same for the domestic and foreign debt and the exchange rate is 1 .

Both countries decide to ask the CAED to issue a notional of 500 Million debt, i.e. 50\% of their financing needs. As it enjoys a credit standing closer to the one of country A, the CAED can issue $20 \%$ of its debt in foreign currency and $80 \%$ in domestic currency, with an issuing cost of $4.3 \%$, i.e. a yearly coupon payment of 43 Million.

$4.5 \%$ is the yearly coupon rate that would have prevailed if the CAED had simply issued the 1 Billion debt and allocated the cash flows and debt service according to country A's and country B's own cost. The cost saving, $0.2 \%$, is equally split between the two countries. Country A receives 500 Million, in exchange of a yearly coupon payment of 15.2 Million in domestic currency and 3.8 Million in foreign currency, which represents a 3.8\% coupon rate on each type of debt. To hedge currency risk, A's government swaps a 3.8 Million payment in domestic currency for a receiving leg of 3.8 Million in foreign currency. The same reasoning holds for country B, which pays an effective $4.8 \%$ on its debt. Furthermore, to hedge its default risk exposure in case of default of B, the government of country A enters a Credit Default Swap (CDS) through which it is paid an insurance premium against the guarantee that it provides. The CDS premium is such that it equates the present value of expected default loss. Naturally, A is free to reinsure its exposure on the CDS market, making the operation neutral.

As illustrated by this simple example, the key reason for success of the CAED is the presence of a comparative advantage at the global level. This is an ex ante argument, as it involves that the event of default is absorbed internally by the consortium of member states and does not contaminate debt issued by the Agency, thereby ensuring its credit standing.

\section{Identifying the cost saving potential}

Why would the creation of the CEAD trigger a positive wealth impacts for its members? There are (at least) three potential reasons for this cost reduction effect.

The first one results from portfolio theory. It relates to a mechanical risk reduction effect through diversification. Starting from the evidence that the investor who purchases sovereign debt issued by several countries bears the individual default risk of each bond in her portfolio, she is exposed to the risk of the weakest link: if one bond defaults, even in the absence of a spillover effect throughout the other countries, the portfolio suffers from the immediate loss. The same reasoning holds, although to a less severe extent, in the event of a downgrade. Now, if the investor purchases debt issued by the CAED, she knows that the internal mechanism governing default at the internal level of the consortium will only have an impact on her patrimony if the severity of the default is such that even the strongest consortium member cannot make up for the loss. She is thus exposed to the strongest link of the group. This possibility to diversify away the specific risks will naturally induce the cost of debt issued by the CAED to be lower than the average cost of debt of its members.

The second one is more political, but can still be explained economically. It relates to an agency cost reduction through a greater verifiability of the countries' actions within than outside the consortium. As the bondholders are dispersed and remote from the debt issuing governments, the consequences of asymmetric information are to be solved by a higher required coupon, i.e. a high yield to maturity. By acting as bankers through the CDS arrangement, the strongest members of the consortium have an incentive to monitor the weakest ones. Furthermore, by sharing the same hierarchical level, they can enforce corrective actions at the political level, which financial markets cannot do directly. By making all governments' actions observable and verifiable, the members of the consortium minimize the cost of information asymmetries, thereby reducing the required credit spread charged to the members.

Finally, there is a liquidity effect. Replacing part of the debt issued by each individual country by a large issue of collective debt potentially reduces the liquidity spread applicable to the bonds. The evidence of Table 1 shows that the potential cost saving is substantial. It should be noted that even German Bunds could also experience a reduction in their liquidity yield, if the CAED issues a large collective debt.

\section{Conditions for sustainability}

The concrete application of this mechanism involves the respect of four main constraints. They involve the presence of a cost advantage, the marking-to-market of all debt components, the seniority of existing sovereign debt over the newly issued debt towards the consortium, and the transparent access to internal and external swap markets. These conditions are detailed below. 


\subsection{Cost saving condition: collective guarantee by the members}

One of the key reservations hindering the creation of Euro-bonds is the clear communication made by rating agencies regarding the type of guarantee by the issuing governments in case of default. The statement is rather clear: if such bonds are issued with a guarantee by each issuer on sum proportional to the government's share in the package, then the rating associated to the bonds will be the lowest amongst the member governments. This is a "weakest link" type of argument: as a rating agency tries to predict the event of default, be it partial, then even if a government announces a default on a very small part of a bond's notional, this is a sufficient triggering event. On the other hand, with a collective guarantee by all the members of the consortium, any weakness from a member would be compensated by the intervention of the stronger members who then performs an "automatic bailout" through the undiscontinued servicing of the outstanding debt. Under this framework, the bonds would presumably receive a rating close or similar to the one of the best issuers. The risk of default would be internalized among the promoters of the CAED.

If Germany, France, the Netherlands, Ireland and Greece guarantee 100 percent of the euro- bond, the rating of this bond should be close to that of Germany or the Netherlands. On the other hand, if Germany guarantees 20 percent, France 15 percent, Ireland 2 percent and Greece 1 percent, the rating of the euro bond should be close to that of Greece.

\subsection{Marking-to-market condition: parallel sovereign bond market}

Figure 3 above clearly shows that the sustainability of the whole mechanism is contingent on the possibility to evaluate the added value of the consortium, through a comparison of the costs of debt with and without the CAED. Note that it is not necessary to know the cost of existing debt on the foreign market: the comparability only involves assessing the total cost of debt in domestic currency, denoted $r_{1}$ in the figure. In concrete terms, beyond the fact that it would not be realistic to let the CAED issue all sovereign debt on behalf of the member governments, this scenario would preclude the marking-to-market of each country's debt, and would make it impossible to assess the cost saving benefits of the mechanism.

\subsection{Seniority of existing sovereign debt}

Beyond the requirement of keeping a market for national sovereign debt active, it is also important that the bond market participants get a fair treatment in the process. Not only should they not be expropriated by the operation, but they should also recognize that the event of default of a country, if it occurs, should primarily affect the members of the consortium. This condition has two justifications. First, the cost saving associated with debt issuance by the CAED comes from the protection of bond investors through the solidarity of the consortium members. If direct sovereign debt defaults before the debt contracted by each country towards the CAED, this second default event becomes very unlikely, and the added value of the bailout mechanism becomes marginal. Second, we argue that the exposure of other member countries to the potential default of a weaker member will trigger reinforced monitoring and will induce greater discipline amongst the consortium members. As a strong country knows that the weaker one will first default on its debt contracted by the CAED, which is junior, its government will exert more pressure to avoid this default. Because information asymmetry issues are less prevalent between sovereign governments than between a government and its bond investors, it is easier to enforce strict discipline within the CAED consortium. Agency conflicts, and their associated costs, are thus lower inside the consortium than on bond markets.

\subsection{Internal and external swap markets}

First, the relations between the CAED and the consortium member states must be governed through the exchange of the proceeds against the stream of cash flows necessary for debt servicing. In order to deliver all initial cash flows in domestic currency, the Agency immediately exchanges the proceeds from foreign debt issuance against the domestic currency, and delivers it to each member state. The dispatching of the coupon payments should correspond to a fair split of the cost advantage between the countries, for instance through a weighted average of the cost saving on the basis of the amounts issued by each party.

Next, the CAED has to pay out the coupons of all debt it has issued, on both domestic and foreign markets. The system must be a pass-through: all coupons and principal repayment paid by the CAED must originate from the sum of flows paid by the member states. It means that each government is responsible for delivering cash flows denominated in foreign currency. In order to hedge this currency risk, the governments must be able to access the currency swap market, and to exchange interest and principal payments in domestic currency against a receiving leg in foreign currency. The proceeds from this swap match the payments to the Agency.

Finally, the possible occurrence of default has to be anticipated inside the consortium. Because the debt contracted by each member with the CAED is junior with respect to the existing sovereign bonds, there is a potential risk of default from each member. To mitigate this risk, the weaker countries should subscribe to an insurance policy against their own 
default. This can be done through an ordinary CDS contract, or through an internal mechanism according to which the stronger countries receive a fee in exchange of the promise to bail out the weaker ones. The former mechanism is obviously more transparent, but induces no particular active interactive monitoring at the government level. For simplicity, we can assume that a fair CDS premium is paid by the weaker countries, "fair" meaning that the present value of the CDS premium leg is equal to the expected default loss at debt inception.

\section{A concrete case study}

Consider three countries belonging to the Eurozone for the illustration: Austria, Belgium and Germany. The choice of these countries is driven by three considerations: the strongest member is present, another country enjoys the top credit rating as well but has not the same "safe harbor" status, and a third country does not encounter particular economic difficulties but is considered, both by rating agencies and by the market, as less solid than the other two.

\section{$\underline{5.1 \text { Data }}$}

The prevailing market and economic conditions prevailing for the three countries of the case study are represented in Table 3.

\begin{tabular}{cccclc}
\hline \hline Country & Total debt (Mio EUR) & Foreign debt & Bond yield (10Y) & Rating & Duration \\
\hline Austria & 170,427 & $4.96 \%$ & $2.74 \%$ & AAA/Aaa & 6.7 \\
Belgium & 310,719 & $0.31 \%$ & $4.03 \%$ & AA+/Aa1 & 5.0 \\
Germany & $1,079,796$ & $0.44 \%$ & $2.01 \%$ & AAA/Aaa & 4.9 \\
\hline \hline
\end{tabular}

Table 3: Debt characteristics for Austria, Belgium and Germany. The total and foreign debt figures are based on the central government marketable debt. The proportion of foreign debt reports the average over the 2005-2010 period. Market and rating data are set to September 2011. The last column reports the average Macaulay duration. Source: OECD’s iLibrary http://stats.oecd.org

Austria and Germany share the same best-in-class credit rating, but their yield on 10-year government debt features a significant difference; Germany being considered as the safest sovereign issuer in euros. Belgium is one notch lower in terms of credit rating, but this translates into a (historically record high) ca. $2 \%$ credit spread over the German Bund. Figure 4 shows the evolution of the total yield spread of Austria (solid line) and Belgium (dotted line)'s 10-year benchmark government bond over the $1999-2010$ period.

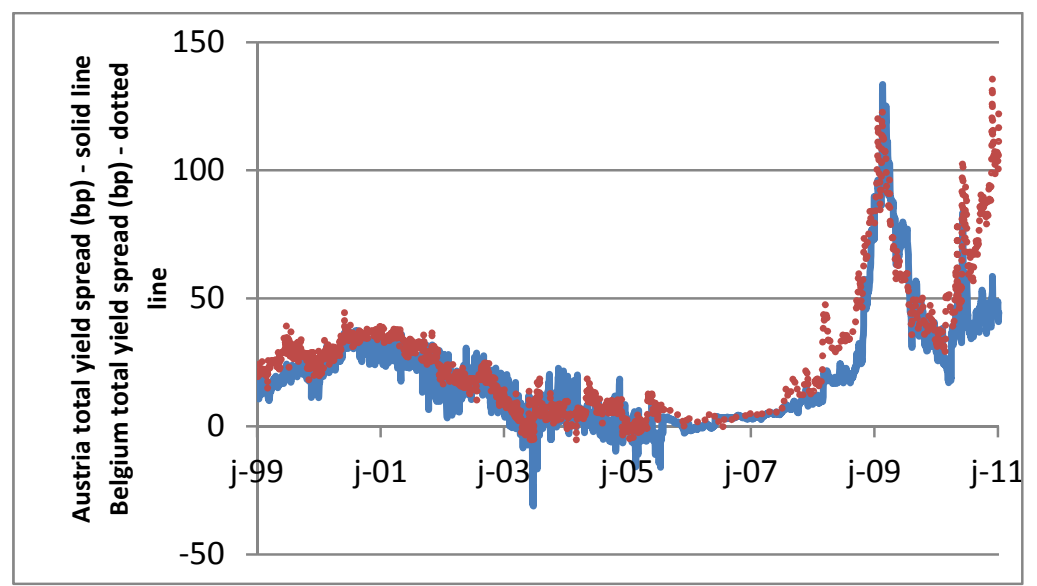

Figure 4: Evolution of Austria (solid line) and Belgium (dotted line)'s 10-year benchmark government yield spread (bp) against the 10-year German bunds over the 1999-2010 period. Source: authors’ computations from Datastream and Bloomberg.

As the total spreads were converging to zero between 2001 and 2007, the recent financial and sovereign debt crises have led the spreads to historical peak. It is interesting to notice that yield spreads were quite similar for Belgium and Austria until 2008. They started to diverge significantly in 2010 with the long government crisis in Belgium. By contrast, after a record high in 2009, Austrian yield spreads have decreased, without however going back to the ex-ante crisis levels (see Figure 4). Besides their credit quality, Austria is the EMU member country with the largest average proportion of foreign debt over the 2005-2010 period. By contrast, Germany and Belgium use virtually no foreign debt in their debt mix.

At the moment of the gathering of these observations, the yield to maturity of the US Treasury securities was about 2.0\%. Given the minute difference with Germany, the benchmark issue in euro, we consider that each country's potential credit spread for a currency swap in dollars is the same as the one in euros. 


\subsection{Mechanism}

Consider that these three countries adhere together to the CAED, and delegate the Agency the responsibility of issuing the amount of debt necessary to meet the yearly refinancing of outstanding debt. Dividing each country's total debt by its Macaulay duration, we reach an aggregate financing need of 308.27 Billion EUR. To ensure consistency with the data, we assume that the target maturity for the newly issued debt is 7 years, with yearly coupon payments. We also assume that the market yield of each country would ensure the issuance of new debt at par for this maturity. ${ }^{2}$ We presume that the optimal proportion of foreign debt to be issued in USD by the Agency is close to the one that prevailed at the time of the EMU advent. From Table 1, this reaches a weighted average of 2\%, or an issue of 6.11 Billion EUR in USD. As the prevailing exchange rate at the moment of the data collection is $1.44 \mathrm{USD} / \mathrm{EUR}$, this amounts to a notional of 8.80 Billion USD.

Because it enjoys a credit rating of AAA/Aaa, the CAED should be able to issue debt at a cost which is close to the one of issuers of similar quality. This holds from the facts that (i) the CAED chooses the optimal mix of domestic and foreign debt on the basis of the dynamics of the respective spreads (see Hübner and Joliet, 2011), and (ii) the collective guarantee warranted by the consortium members improves their overall credit quality by a default risk diversification argument. In the present case, the yield to maturity that would make each country neutral with respect to the issuance of new debt by the CAED and with own debt issuance in isolation is $2.48 \%$. That is, if the CAED issues new debt at this coupon rate and dispatches the cash flows and debt service according to each country's funding cost, there will be no gain/loss for any of these countries. To assess the cost saving, we posit that the "implicit" credit rating of Belgium according to its role in the CAED would be similar to the one of Austria, as its default would trigger a bailout from the other two countries that results in no default for the end investors. This reasoning yields a coupon rate of 2.22\%, corresponding to a saving of $0.26 \%$ or a yearly 802.7 Million EUR.

Assuming further that the cost saving is shared amongst the members according to their respective share in the debt issuance of the CAED, we get that Austria should receive $8.27 \%$ of the saving, or 66.45 Million EUR. Similarly, the saving for Belgium is 162.03 Million EUR (20.2\% of the total) and for Germany 574.23 Million EUR (71.5\%). In terms of yearly reduction of interest cost, we get that each country saves the same flat 26 bps on their debt.

Note that the cost of the CDS premium that the weakest countries would have to pay to Germany in order to organize the bailout if necessary is compensated by the cost saving on their existing debt. Consider that the operation is neutral for Austrian debt. For Belgian debt, we streamline the approach by considering that the credit spread of $2.02 \%$ on existing debt results from the product of a loss rate in case of default and the probability of default ${ }^{3}$. This framework corresponds to the "recovery of market value" approach introduced by Duffie and Singleton (1999). Applying the standard recovery rate of $40 \%$ which is common practice for default estimation, this leaves out a probability of default of $3.37 \%$. Assuming a waterfall structure where existing marketable debt is more senior than internal debt, we apply a flat increase of the probability of defaulting on debt towards the CAED, compensated by an equivalent decrease of the probability of defaulting existing debt, so that the resulting present value of debt is unchanged. ${ }^{4}$ Since approximately $20 \%$, or 62.225 Billion EUR, of existing debt is retired, we apply the same proportionality coefficient to the new default probability, and get $3.37 \% \times 80 \%=2.69 \%$. The yield on Belgian market debt becomes $3.63 \%$. Consequently, the default spread applicable to the amount owed to the CAED is $3.77 \%$, for a yield of $5.78 \%$. In other terms, since Belgium should pay a coupon rate of $4.03 \%$ to the CAED in the absence of any wealth effect from the consortium, it would have to pay an additional $5.78 \%-4.03 \%=1.75 \%$ CDS premium to Germany in order to insure the German government against the event of default.

Figure 5 summarizes the simulated mechanism of the consortium within the same framework as in Figure 3.

\footnotetext{
${ }^{2}$ This means that we assume that the 7-year debt bears the same par yield as the benchmark 10-year debt.

${ }^{3}$ We put aside the liquidity component of the spread, but this does not alter the quality of the outputs.

${ }^{4}$ The actual change in the probability of default is irrelevant for the illustration. This is a neutral operation since the government's credit standing is unchanged from the operation, and so the present value of all debt remains unaffected. Our illustration only serves as a way to identify the potential conditions of the CDS to be designed between the German and Belgian governments.
} 


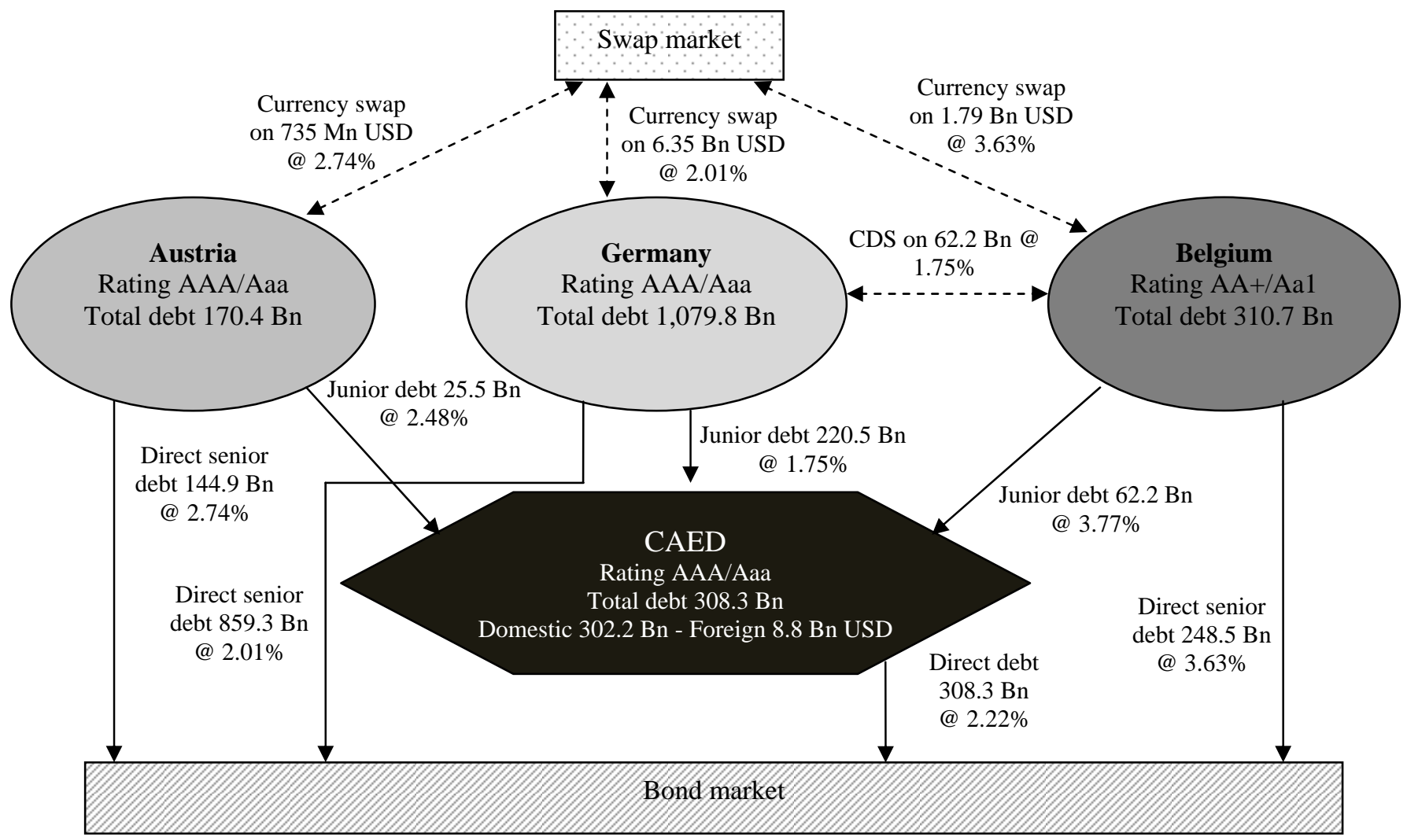

Figure 5: case study results with the functioning of CAED

\section{Concluding remarks: where does this mechanism help}

A natural question that arises when confronted to the sovereign crisis of 2010-11 is: would the issuance of Euro-bonds through this kind of mechanism help? This question should be discussed at two levels: (i) the added value of the system compared to alternative models of issuing Euro-bonds, and (ii) the effectiveness of the mechanism in front of a crisis.

\subsection{The CAED versus alternative ways to issue Euro-bonds}

First, note that the system proposed in this paper goes beyond the pure pooling of several countries' government debt under a single guarantee, as most of the discussions that took place in 2011 were about. In case of such a minimalist solution, what would be the gains to be expected from the issue? They would probably be equivalent in terms of market liquidity and, to some extent, regarding the possibility to monitor the members of the consortium, thereby inducing an agency cost reduction effect.

However, there are three ways in which the solution proposed in this paper is more cost effective than straight Eurobonds. First, we argue that the reservations that countries like Germany would put forward against the system, namely a higher cost of debt, are more likely to be valid without than with the CAED. By contracting debt against the Agency instead of against the bond market, the redistribution of the interest saving among the consortium is objective and transparent. That is, a country like Germany will not accept to contribute to the system if the CAED would charge a rate which is higher than the cost of direct debt. Second, the CAED system accepts a broader membership than a consortium of countries that would wish to pool their bond issue. We justify this claim by the fact that all debt contracted within the consortium is junior to national sovereign bonds. In case of direct Euro bond issuance, these bonds must share (at least) the same level of seniority as existing bonds. Thus, there is no interest saving for the existing bonds, and the whole system is at risk of default of the weakest member country. If a country like Greece participates to the issue, the possible event of its default has the same effect on the other members' spreads as if they had to bail out Greece at once, for instance through the European Financial Stability Facility (EFSF). As a matter of fact, the proposed Euro bond system has been thought of as a "club" of contributing countries with a good credit standing, but not as a pan-European system meant to pool resources of all EMU members, including the ones that are in financial distress. Last but not least, the proactive role of the CAED in terms of deciding which type of debt to issue on what type of market and with what maturity mix is only possible if the CAED exists and is endowed with this privilege. As this is a way to reduce the 
global cost of debt for the EMU members, resigning the creation and the functioning of this Agency potentially also leads to the avoidance of a substantial source of cost saving.

On the other hand, in political terms, the CAED serves as a technical and not a political institution. This introduces an important nuance, as the proposed system does not induce any potential loss in sovereignty in terms of the level and maturity of debt that is considered necessary to run each country's economy. We escape thus a quite tricky issue, namely the creation of a new institution that would erode the sovereign prerogatives of the member countries without reaching greater budgetary, fiscal or political integration at the same time. The creation of a more powerful type of agency would simply not be possible under the political situation prevailing 12 years after the advent of EMU.

\subsection{The CAED and the sovereign debt crisis}

Would the system have prevented, mitigated or cured the sovereign crisis in 2010-11? We argue that, even though the mechanism is not meant to address these kinds of crises ex ante, it could certainly contribute to a partial resolution of the crisis.

As stated before, the CAED membership should not be viewed as a "club", because such a standpoint would add no value to the system. Countries that could potentially get into difficulties could and should adhere to the consortium. By retiring existing debt and replacing it with debt towards the CAED, a government that experiences significant default risk reduces the market pressure (because senior debt is smaller thanks to the retirement of marketable debt), which it leads other consortium members to get a closer and more proactive role in the resolution of the crisis, just like what the EFSF mechanism is supposed to lead to.

Furthermore, the internal CDS mechanism involves the member countries, and does not lend itself to market manipulations by speculative investors. The spikes observed on several countries' sovereign CDS could have been reduced by the fact that a "parallel" market, involving governments only, would be running. Since direct national debt is senior with respect to the debt issued in the consortium, the CDS spread should be lower. Any speculative movement that would lead this spread to become higher would trigger an immediate arbitrage reaction by the member governments, with as a consequence of profit made by sovereign countries at the detriment of speculators.

Finally, if such an Agency had been active when the sovereign crisis burst, the governments under market pressure (not only Greece, but also Ireland and Portugal, and next Italy and Spain) could have refinanced a substantial amount of debt through a higher stake in the CAED consortium, under the agreement of other countries, thereby benefitting from the implicit guarantee of the other governments on the refinanced debt. This would have avoided part of the vicious circle that the Greek economy suffered because of the necessity to refinance its own debt.

The crisis would probably not have been avoided because there is no adequate purely technical solution to a fundamental problem. If a country defaults, all creditors will lose the defaulted amount collectively. But the responsibilities and the causal relationships could have been made sounder and more explicit with the CEAD system, where the monitoring is immediately in the hands of the consortium members, than under what happened in reality, where the bondholders had indeed little influence on the economic path followed by the weakest countries before and during the crisis. 


\section{References}

Beber, A; Brandt, M.; and Kavajecz, K.(2009) "Flight-to-Quality or Flight-to-Liquidity? Evidence From the Euro-Area Bond Market."Review of Financial Studies, 22, 925-957.

Codogno, L.; Favero, C.; and Missale, A. (2003) "Yield spreads on EMU government bonds." Economic Policy, 18, 503-532.

Duffie, D., and Singleton, K. (1999) "Modeling term structures of defaultable bonds." Review of Financial Studies, 12, 687-720.

Favero, C.; Giavazzi, F.; and Spaventa, L.(1997) "High yields: the spread on German interest rates." The Economic Journal, 107, 956-985.

Favero, C.; Pagano, M.; and Von Thadden E.-L. (2010) "How does liquidity affect government bond yields?." Journal of Financial and Quantitative Analysis, 45, 107-134.

Gomez-Puig, M. (2008). "Monetary integration and the cost of borrowing." Journal of International Money and Finance, 27, 455-479.

Gomez-Puig, M.(2006) "Size matters for liquidity: evidence from EMU sovereign yield spreads." Economics Letters, 90, 156-162.

Hübner, G., and Joliet, R. (2011), “Government Debt Denomination and Maturity Policies before and after the EMU Advent”, Working paper.

Manganelli, S., and Wolswijk, G.(2007)"Market discipline, financial integration and fiscal rules. What drives spreads in the euro area government bond market?". European Central Bank Working Paper no. 745.

Nielsen, L. (1999)"Yield spreads and optimal public debt management under the single currency." In: European Capital Markets with a Single Currency, Dermine, J., and Hillion, P., Eds, Oxford University Press . 